\title{
Clearance of jaundice after the modified Kasai's operation predicts survival outcomes in patients with biliary atresia
}

\author{
Jinchanya Tamgal ${ }^{1}$, Alisara Damrongmanee ${ }^{1}$, Jiraporn Khorana ${ }^{2}$, Kanokkan Tepmalai ${ }^{2}$, \\ Nuthapong Ukarapol ${ }^{1}$ \\ Departments of ${ }^{1}$ Pediatrics and ${ }^{2}$ Surgery, Chiang Mai University, Faculty of Medicine, Thailand. E-mail: nukarapo@gmail.com \\ Received: 21st February 2018, Revised: 14th March 2018, Accepted: 27th March 2018
}

SUMMARY: Tamgal J, Damrongmanee A, Khorana J, Tepmalai K, Ukarapol N. Clearance of jaundice after the modified Kasai's operation predicts survival outcomes in patients with biliary atresia. Turk J Pediatr 2019; 61: 7-12.

The aim of this study was to assess the probability of survival with native liver (SNL) and the rate of esophageal variceal bleeding (EVB) as well as their potential risk factors, in patients diagnosed with Biliary Atresia (BA), who underwent the hepaticoportoenterostomy (HPE) by retrospectively reviewing medical records between 2007 and 2016. The subjects were classified as poor outcomes if they died or a liver transplant (LT) was performed. A total of 73 cases were enrolled. The average age at HPE was 106.2 +/- 58.5 days. Poor outcome was observed in $27.4 \%, 54.8 \%$ survived with native liver and $17.8 \%$ were lost to follow-up. The principal cause of death was sepsis, followed by massive upper GI hemorrhage. The overall 10-year SNL was $66.8 \%$. Only total bilirubin (TB) $>3 \mathrm{mg} / \mathrm{dL}$ at 3, 6 months after HPE and presence of associated anomalies negatively affected SNL $(p=0.0155,0.0042$ and 0.001 , respectively). Most of the patients experienced EVB within 3 years of age, in which TB $>9 \mathrm{mg} / \mathrm{dL}$ at 12 months after HPE was significantly associated with probability of the EVB outcome. Any interventions to improve jaundice clearance after HPE should be strongly pursued in order to improve outcomes in BA patients, particularly in centers where liver transplantation (LT) is not available. Surveillance esophagogastroduodenoscopy around the age of 1.5 years in patients having TB $>9 \mathrm{mg} / \mathrm{dL}$ may be beneficial to identify large varices having potential fatal bleeding.

Key words: biliary atresia, prognosis, survival, esophageal variceal bleeding.

Biliary atresia is a progressive obliterative extrahepatic bile duct disease with an approximate prevalence of 1:6,000 - 1:18,000 live births. ${ }^{1}$ It is one of the common causes of prolonged neonatal jaundice in Thailand, comprising $22 \% .^{2}$ The pathogenesis remains unclear; however, infections, immune dysregulation, vascular abnormalities, defective morphogenesis, and environmental toxin exposure have been postulated as potential risks in children with genetic susceptibility. ${ }^{3}$ Although several studies have tried to look for the most timely accurate and reliable diagnostic tool, there has been no such single non-invasive investigation confidently establishing the correct diagnosis, except the gold standard of intraoperative cholangiography. At our center, the diagnosis is relied on a combination of various laboratory tests, including: Gammaglutamyl transferase (GGT) $>500 \mathrm{IU} / \mathrm{mL}$, presence of triangular cord (TAC) sign detected by ultrasonography, no excretion of radiotracer by DISIDA scan, and/or bile duct proliferation from liver pathology. ${ }^{4,5}$ Finally, it has to be confirmed by intraoperative cholangiography.

Hepaticoportoenterostomy (HPE) within 60 days of life has been generally accepted as the mainstay of therapy for biliary atresia. However, long-term outcome, particularly survival with native liver (SNL), has been unsatisfactory. Although liver transplantation has recently improved overall survival, it causes immunosuppression and its related surgical and medical complications. Many predictive factors for long-term outcomes of biliary atresia have been studied with inconclusive results. This 
study aimed to assess the probability of SNL and rate of esophageal variceal bleeding (EVB) as well as their potential risk factors.

\section{Material and Methods}

This was a retrospective cohort study (20072016) enrolling biliary atresia patients who were investigated, diagnosed, and underwent standard open modified Kasai's operation (HPE) at Chiang Mai university hospital, a referral tertiary care center in the North of Thailand. The operations were performed by 3 surgeons during the study period. The definite diagnosis was relied on evidence of no excretion of radiotracer into the gallbladder and small bowel up to 24 hours by the DISIDA scan and/ or the presence of compatible characteristic findings detected either by the intraoperative cholangiography or surgical pathology. Initial clinical and biochemical data were retrieved from electronic medical records.

The primary outcome of this study was survival status, categorized as SNL and death/liver transplant which were indicative of the poor outcome. Occurrence of the first variceal bleeding was assessed as the secondary outcome. For patients who were lost to follow up, we made a phone call to their families for the decisive status, particularly those who died. Total bilirubin (TB) closest to the $3^{\text {rd }}$, $6^{\text {th }}$, and $12^{\text {th }}$ month after HPE were reviewed, as well as the evidence of variceal bleeding and postoperative cholangitis. Postoperative cholangitis was defined as having a fever accompanied with presence of new episode of jaundice, significant increase in TB, or acholic stools. In accordance to the literature review, we selected some promising factors that may influence the SNL, including age at HPE, bile flow which was subjectively assessed by the surgeons during the operation, type of biliary atresia, clearance of jaundice $(\mathrm{TB}<3 \mathrm{mg} / \mathrm{dL})$ after HPE at 3 and 6 months, postoperative cholangitis, postoperative corticosteroids, presence of significant associated anomalies, particularly with congenital heart diseases, fibrosis shown on liver biopsy, and presence of (TAC) sign by ultrasound. Some of our patients who failed HPE underwent livingdonor liver transplantation (LT). However, we had not systematically set criteria to refer patients for liver transplant, because we were at the beginning of the program. If there was no esophageal variceal bleeding reported, the patients would be scheduled for a surveillance

Table I. Factors Influencing Survival with Native Liver.

\begin{tabular}{|c|c|c|c|c|}
\hline \multirow[b]{2}{*}{ Factors } & \multicolumn{2}{|c|}{ Univariate analysis $\dagger$} & \multicolumn{2}{|c|}{ Multivariate analysis\$ } \\
\hline & N (\%) & $\mathrm{p}$ value & $\begin{array}{l}\text { Hazard ratio } \\
(95 \% \mathrm{CI})\end{array}$ & $\mathrm{p}$ value \\
\hline Gender (male) & $34(46.58)$ & 0.7432 & & \\
\hline Age at HPE $>60 \mathrm{~d}$ & $63 / 71(88.73)$ & 0.3540 & & \\
\hline Age at $\mathrm{HPE}>70 \mathrm{~d}$ & $57 / 71(80.28)$ & 0.0628 & & \\
\hline $\mathrm{TB}<3 \mathrm{mg} / \mathrm{dL}$ at $3 \mathrm{mo}$ after HPE & $16 / 62(25.81)$ & 0.0155 & $0.43(0.04,4.78)$ & 0.493 \\
\hline $\mathrm{TB}<3 \mathrm{mg} / \mathrm{dL}$ at 6 mo after HPE & 26/54 (48.15) & 0.0042 & $0.24(0.04,1.39)$ & 0.111 \\
\hline Poor bile flow & $14 / 52(26.92)$ & 0.1173 & & \\
\hline Type 3 BA & $51 / 59(86.44)$ & 0.4492 & & \\
\hline Postoperative cholangitis & $40 / 62(64.52)$ & 0.1068 & & \\
\hline Postoperative corticosteroids & $15 / 70(21.43)$ & 0.3297 & & \\
\hline Presence of associated anomalies & $5 / 70(6.85)$ & 0.0010 & - & 1 \\
\hline Fibrosis on liver biopsy & $16 / 22(72.73)$ & 0.6594 & & \\
\hline TAC by US & $48 / 69(69.57)$ & 0.3448 & & \\
\hline
\end{tabular}

$\dagger$ log-rank test, $\$$ Cox regression

Abbreviation: $\mathrm{BA}=$ biliary, $\mathrm{CI}=$ confident interval, $\mathrm{d}=$ day, $\mathrm{HPE}=$ Hepaticoportoenterostomy, atresia, $\mathrm{mo}=\mathrm{month}, \mathrm{N}=$ number, $\mathrm{TAC}=$ triangular cord, $\mathrm{TB}=$ total bilirubin, $\mathrm{US}=$ ultrasound 


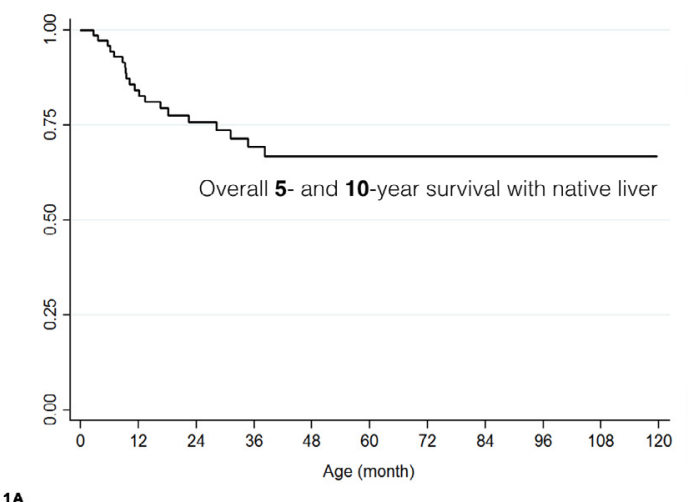

14
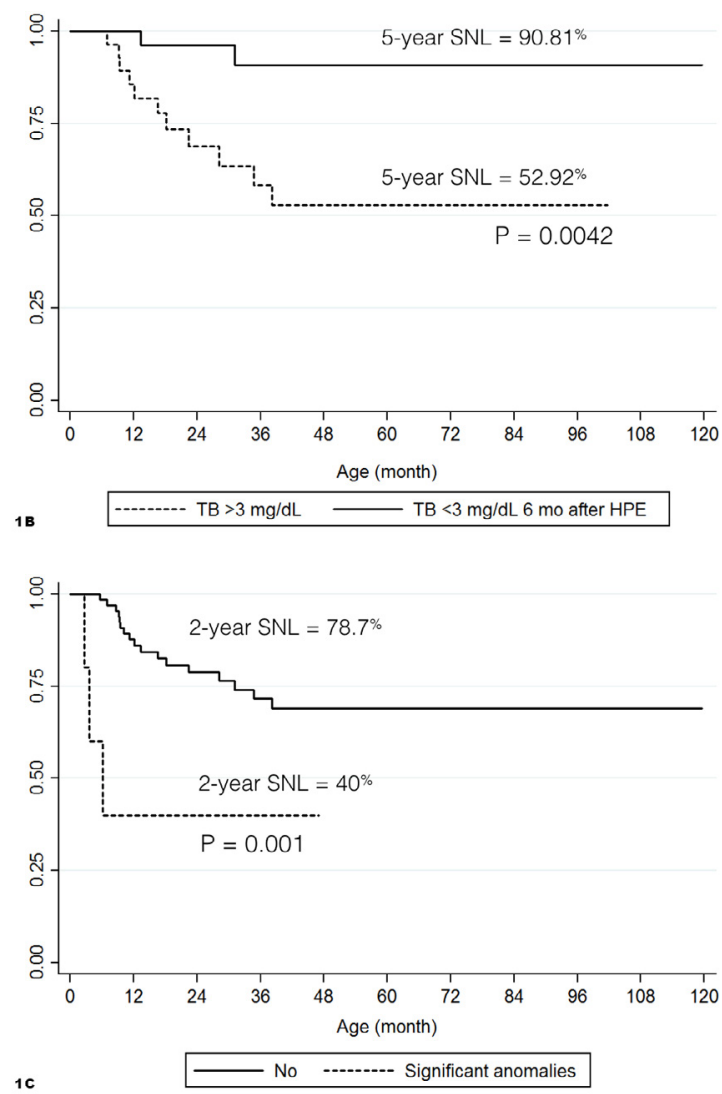

Fig. 1A Overall survival with native liver in biliary atresia patients.

Fig. 1B Survival with native liver in biliary atresia patients stratified by clearance of jaundice 3 months after hepaticoportoenterostomy.

Fig. 1C Survival with native liver in biliary atresia patients stratified by presence of significant associated anomalies.

program for varices after 2 years of age.

This study was approved by the Research Ethics Committee of the Faculty of Medicine, Chiang Mai University (PED-2559-03993). All procedures performed in the study involving human participants were in accordance with the ethical standards of the institutional and/or national research committee and with the 1964 Helsinki declaration and its later amendments or comparable ethical standards.

\section{Statistical analysis}

The STATA program v.12 was applied for all statistical studies, in which the principal analysis was the determination of the study outcomes using the Kaplan-Meier survival estimation model. To determine potential factors influencing SNL, the univariate analysis was calculated by the log-rank test, whereas the Cox regression model was applied for the multivariate analysis. A non-parametric test, the rank sum test, was used to compare continuous data between groups. A p value $<0.05$ was considered statistically significant.

\section{Results}

A total of 73 cases were enrolled with an average case load of 7.3 cases/year. The mean follow-up time was 38.42 months. We observed two peaks of seasonal variation pattern during August to October and December to February, respectively. Twenty of the cases were classified into the poor outcome group, in which 5 underwent LT and 15 died without LT. Total death were 17 , including 2 patients with LT. Sepsis $(n=9)$ was the most common cause of death, followed by massive upper GI bleeding $(n=3)$, liver failure $(n=2)$, immediate complications of LT $(n=2)$, and unknown $(n=1)$. In the LT group, the mean Pediatric End-stage Liver Disease score (PELD) was 21 with a range of 15-22. Two died from vascular complications, portal vein and hepatic artery thrombosis, and hepatic vein thrombosis with fungal infection, respectively. Thirteen cases were lost to follow-up. The 5- and 10-year overall survival with native liver were $66.8 \%$ and $66.8 \%$, respectively in this study. (Fig. 1A) Five of 73 had significant associated anomalies, including heterotaxy syndrome, VSD/ASD, cleft lip and cleft palate, craniosynostosis, and clubfoot, respectively. Of 71 cases who had HPE done, the average age at surgery and waiting time after admission to definite HPE were $106.2+/-58.5$ and $16.72+/-10.8$ days, respectively. Of those who died in this 
Table II. Review on Factors Negatively Influencing Survival with Native Liver Among Studies.

\begin{tabular}{|c|c|c|c|c|}
\hline Study & Country & $\mathrm{N}$ & Year & Factors negatively influencing SNL \\
\hline Chung PHY 13 & HKG & 185 & $1980-2012$ & Repeated cholangitis \\
\hline Nighingale $S 9$ & AUS & 217 & $1986-2009$ & $\begin{array}{l}\mathrm{TB}>4.3 \mathrm{mg} / \mathrm{dL} \text { at } 3 \mathrm{mo} \text { after HPE } \\
\mathrm{Alb}<3.5 \mathrm{~g} / \mathrm{dL} \text { at } 3 \mathrm{mo} \text { after HPE }\end{array}$ \\
\hline de Vries WD ${ }^{11}$ & NLD & 214 & $1987-2008$ & $\begin{array}{l}\text { HPE after age of } 60 \text { days } \\
\text { TB }>1.17 \mathrm{mg} / \mathrm{dL} \text { at } 6 \mathrm{mo} \text { after HPE } \\
\text { No antibiotic use }\end{array}$ \\
\hline Koga $\mathrm{H}^{8}$ & JPN & 60 & 1989-2012 & $\begin{array}{l}\mathrm{TB}>1.2 \mathrm{mg} / \mathrm{dL} \text { at } 2 \mathrm{mo} \text { after HPE } \\
\text { Postop. cholangitis } \mathrm{w} / \mathrm{n} 3 \mathrm{mo} \text { after HPE }\end{array}$ \\
\hline Goda T 12 & JPN & 54 & $1990-2010$ & $\begin{array}{l}\mathrm{DB}>0.7 \mathrm{mg} / \mathrm{dL} \text { at } 2 \mathrm{mo} \text { after } \mathrm{HPE} \\
\mathrm{AST}>94 \mathrm{IU} / \mathrm{L} \text { at } 2 \mathrm{mo} \text { after } \mathrm{HPE}\end{array}$ \\
\hline Shneider BL ${ }^{7}$ & USA & 104 & $1997-2000$ & $\mathrm{~TB}>2 \mathrm{mg} / \mathrm{dL}$ at $3 \mathrm{mo}$ after $\mathrm{HPE}$ \\
\hline Davenport M 10 & UK & 443 & 1999-2009 & $\begin{array}{l}\text { Presence of anomalies } \\
\text { Type } 3 \text { BA }\end{array}$ \\
\hline Chuslip S 14 & THA & 133 & $2000-2014$ & $<20 \%$ decrease in TB 7 days after HPE \\
\hline This study & THA & 73 & $2007-2016$ & $\begin{array}{l}\mathrm{TB}>3 \mathrm{mg} / \mathrm{dL} \text { at } 6 \mathrm{mo} \text { after HPE } \\
\text { Presence of anomalies }\end{array}$ \\
\hline
\end{tabular}

Abbreviation: $\mathrm{BA}=$ biliary atresia, $\mathrm{HPE}=$ Hepaticoportoenterostomy, atresia, $\mathrm{mo}=$ month, $\mathrm{N}=$ number, Postop. $=$ postoperative, $\mathrm{TB}=$ total bilirubin, $\mathrm{DB}=$ direct bilirubin, $\mathrm{SNL}=$ survival with native liver, $\mathrm{AUS}=$ Australia, HKG=Hong Kong, JPN=Japan, $\mathrm{NLD}=$ Netherlands, $\mathrm{THA}=$ Thailand, $\mathrm{UK}=$ United Kingdom, USA $=$ United States of America

cohort, the average duration between HPE and death was 11.79 months with a range of 0.17-35.63 months. Those who had ultrasound and liver biopsy performed, $69.6 \%$ and $72.7 \%$ showed the triangular cord sign and hepatic fibrosis, respectively. Of the cases $86.4 \%$ were identified as type 3 biliary atresia by either IOC or operative findings.

Regarding the primary outcomes, only the level of $\mathrm{TB}<3 \mathrm{mg} / \mathrm{dL}$ at 3 and 6 months after HPE and the presence of associated anomalies statistically significantly influenced survival with native liver with a $\mathrm{p}$ value of $0.0155,0.0042$, and 0.001 , respectively. (Table I and Fig. 1B, 1C) Although the clearance of jaundice at 6 months after HPE tended to be the most important factor against the poor outcome with a hazard ratio of $0.24(95 \%$ CI of 0.04-1.39), it did not reach a statistical significance analyzed by multivariate analysis using the Cox regression model. Apart from those mentioned earlier, neither initial clinical data nor biochemical tests were able to predict the primary outcomes.
About half of the cases developed variceal bleeding within the first five years of age, in which most of them presented within 36 months. This study showed that the patients with variceal bleeding had significant higher level of TB at 12 months after HPE compared to those without this symptom with an average of 13.6 and $4.3 \mathrm{mg} / \mathrm{dL}$, respectively. $(\mathrm{p}=0.0183)$ The Kaplan-Meier survival analysis of EVB identified significant poor outcome in patients having $\mathrm{TB}>9 \mathrm{mg} / \mathrm{dL}$ at 12 months after HPE. (Fig. 2)

\section{Discussion}

The study showed acceptable institutional case load with the average of 7.3 cases/ year. With continuous learning experience, our survival with native liver after HPE was comparable with international outcomes $(67 \%$ vs. $24-52.8 \%) .{ }^{6}$ Although pathogenesis of the biliary atresia is still unknown, we observed a pattern of seasonal variation which was consistent with the results of $27.5 \%$ of world reports on incidence of biliary atresia. This may 


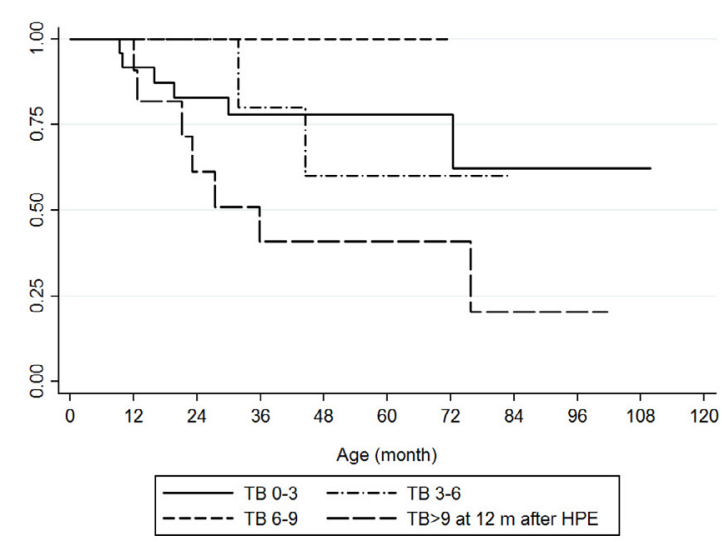

Fig. 2 Esophageal variceal bleeding in biliary atresia patients stratified by total bilirubin level at 12 months after hepaticoportoenterostomy.

partly suggest an infection-associated etiology although it is not strong enough to make a definite conclusion. It was not surprising that most of the cases $(72.7 \%)$ showed advanced fibrosis on liver biopsy. This could be associated with the older average age at diagnosis and longer waiting time for HPE than those reported from Western countries. ${ }^{7}$

Biliary cirrhosis and end-stage liver disease is the ultimate outcome for the patients with failure of HPE. Inability to establish bile flow and recurrent postoperative cholangitis have been shown as potential risks of death or LT in several studies. ${ }^{7-9}$ Despite inconsistent definition, failure to achieve being jaundicefree at a certain period of time after HPE seems to be commonly attributed to the poor outcome. $^{7-14}$ (Table II). Only impaired clearance of jaundice ( $\mathrm{TB}<3 \mathrm{mg} / \mathrm{dL})$ at 3, 6 months after HPE and the presence of significant associated anomalies led to the poor outcome in our series. However, this significance was lost after running the Cox regression model for multivariate analysis. This may have resulted from limited number of jaundice-free patients due to late HPE in our study, in which this may affect the power of the test model. Ongoing inflammation with progressive obliterative bile duct destruction resulting from long-standing exposure to toxic bile acids during cholestasis is responsible for end-stage liver disease. ${ }^{15}$ In centers where LT is not available, it may be difficult to achieve long-term survival and a good quality of life in the patients with high PELD score. Hence, any interventions to enhance clearance of jaundice should be robustly implemented. These would include strategies for early diagnosis and treatment, improvement in surgical technique, centralized operation in experience centers, appropriate nutritional support, and development of effective drug and corticosteroid regimens for cholestasis. Although a large cohort from UK did not find an association between age at surgery and survival with native liver, we should continue to put a strong effort to increase public and health-care professional awareness on this issue. ${ }^{10}$ Stool color chart is a good tactic to alert both family members and physicians for early referral. ${ }^{16}$

About half of our patients experienced EVB at the age of 5 years and most of them encountered the first bleeding episode within the first 3 years of life. As mentioned previously, upper GI bleeding comprised the second most common cause of death in biliary atresia patients. It also caused complications in patients with sepsis. Therefore, an appropriate surveillance EGD program in biliary atresia patients should be attentively established. Unfortunately, pediatric guidelines have mainly applied extrapolated data from studies in adults. We observed that the average TB level at 12 months after HPE was significant higher in those experiencing EVB. After performing subgroup analysis, patients with $\mathrm{TB}>9 \mathrm{mg} / \mathrm{dL}$ were at significant risk of variceal bleeding. To make an early detection and provide primary prophylaxis, we recommend surveillance EGD program in biliary atresia patients at 1.5 years old if their TB level are still greater than $9 \mathrm{mg} / \mathrm{dL}$. Either propranolol or endoscopic band ligation can be considered as an option for patients with large varices noted at the screening. In accordance to the European and US survey, if large EVs are not seen, most of the experts continue to schedule annual upper endoscopy for surveillance in cirrhotic patients with portal hypertension. ${ }^{17}$

The overall 10 -year SNL was $66.8 \%$ in our study, comparable with those reported internationally. Any interventions aiming to improve jaundice clearance after HPE should be strongly pursued to improve survival outcome in biliary atresia patients, particularly in centers where LT is not available. EVB is one of common complication and was the second most common cause of 
death in this study. Surveillance EGD around the age of 1.5 year in patients with $\mathrm{TB}>9 \mathrm{mg} /$ $\mathrm{dL}$ may be beneficial to identify large varices posing potential fatal bleeding.

\section{REFERENCES}

1. Chardot C, Carton M, Spire-Bendelac N, Le Pommelet C, Golmard JL, Auvert B. Epidemiology of biliary atresia in France: A national study 1986-96. J Hepatol 1999; 31: 1006-1013.

2. Aanpreung $\mathrm{P}$, Laohapansang $\mathrm{M}$, Ruangtrakool R, Kimhan J. Neonatal cholestasis in Thai infants. J Med Assoc Thai 2005; 88(Suppl 8): S9-S15.

3. Sokol RJ, Mack C, Narkewicz MR, Karrer FM. Pathogenesis and outcome of biliary atresia: Current concepts. J Pediatr Gastroenterol Nutr 2003; 37: 4-21.

4. Ukarapol N, Wongsawasdi L, Ong-Chai S, Riddhiputra P, Kongtawelert P. Hyaluronic acid: Additional biochemical marker in the diagnosis of biliary atresia. Pediatr Int 2007; 49: 608-611.

5. Visrutaratna $\mathrm{P}$, Wongsawasdi L, Lerttumnongtum $\mathrm{P}$, Singhavejsakul J, Kattipattanapong V, Ukarapol N. Triangular cord sign and ultrasound features of the gall bladder in infants with biliary atresia. Australas Radiol 2003; 47: 252-256.

6. Jimenez-Rivera C, Jolin-Dahel KS, Fortinsky KJ, Gozdyra $\mathrm{P}$, Benchimol EI. International incidence and outcomes of biliary atresia. J Pediatr Gastroenterol Nutr 2013; 56: 344-354.

7. Shneider BL, Brown MB, Haber B, et al; Biliary Atresia Research Consortium. A multicenter study of the outcome of biliary atresia in the United States, 1997 to 2000. J Pediatr 2006; 148: 467-474.
8. Koga H, Wada M, Nakamura $\mathrm{H}$, et al. Factors influencing jaundice-free survival with the native liver in post-portoenterostomy biliary atresia patients: Results from a single institution. J Pediatr Surg 2013; 48: 2368-2372.

9. Nightingale S, Stormon MO, O'Loughlin EV, et al. Early posthepatoportoenterostomy predictors of native liver survival in biliary atresia. J Pediatr Gastroenterol Nutr 2017; 64: 203-209.

10. Davenport M, Ong E, Sharif K, et al. Biliary atresia in England and Wales: Results of centralization and new benchmark. J Pediatr Surg 2011; 46: 1689-1694.

11. de Vries W, de Langen ZJ, Groen H, et al; Netherlands Study Group of Biliary Atresia and Registry (NeSBAR). Biliary atresia in the Netherlands: outcome of patients diagnosed between 1987 and 2008. J Pediatr 2012; 160: 638-644.e2.

12. Goda T, Kawahara H, Kubota A, et al. The most reliable early predictors of outcome in patients with biliary atresia after Kasai's operation. J Pediatr Surg 2013; 48: 2373-2377.

13. Chung PH, Wong KK, Tam PK. Predictors for failure after Kasai operation. J Pediatr Surg 2015; 50: 293296.

14. Chusilp S, Sookpotarom P, Tepmalai K, et al. Prognostic values of serum bilirubin at 7 th day post-Kasai for survival with native livers in patients with biliary atresia. Pediatr Surg Int 2016; 32: 927-931.

15. Li T, Apte U. Bile acid metabolism and signaling in cholestasis, inflammation, and cancer. Adv Pharmacol 2015; 74: 263-302.

16. Gu YH, Yokoyama K, Mizuta K, et al. Stool color card screening for early detection of biliary atresia and long-term native liver survival: A 19-year cohort study in Japan. J Pediatr 2015; 166: 897-902.e1.

17. D'Antiga L. Medical management of esophageal varices and portal hypertension in children. Semin Pediatr Surg 2012; 21: 211-218. 